Health \& Medicine | Edgar Pick

\section{Reactive oxygen species are at the heart of innate immunity}

\begin{tabular}{|c|c|}
\hline $\begin{array}{l}\text { Our innate immune system } \\
\text { is our first line of defence } \\
\text { against disease. At the heart } \\
\text { of this response is an enzyme } \\
\text { complex, called NADPH } \\
\text { oxidase, which produces a form } \\
\text { of reactive oxygen molecule to } \\
\text { destroy invading pathogens. } \\
\text { Professor Edgar Pick of Tel } \\
\text { Aviv University, has made } \\
\text { a huge contribution to this } \\
\text { field of research, enhancing } \\
\text { our understanding of the } \\
\text { foundations of innate immunity } \\
\text { in many different ways. The } \\
\text { discoveries made by Professor } \\
\text { Pick and his colleagues could } \\
\text { allow the development of } \\
\text { treatments for a number of } \\
\text { serious illnesses. }\end{array}$ & $\begin{array}{l}\text { to are born with the ability } \\
\text { immunt disease. Our innate } \\
\text { the genes we inherit from, driven by barents, is } \\
\text { our first line of defence against invading } \\
\text { pathogens. Unlike our adaptive immune } \\
\text { response, which remembers our previous } \\
\text { encounters with particular pathogens } \\
\text { (including bacteria and viruses) and } \\
\text { mounts a target-specifici response, the } \\
\text { innate immune system is non-specific. } \\
\text { Instead, it acts as a first and fast blockade } \\
\text { to infection. The innate immune system } \\
\text { includes physical barriers, like the skin, } \\
\text { chemical mediators, and a variety of cells } \\
\text { that destroy invading pathogens. } \\
\text { The group of cells that fight infection } \\
\text { are the leucocytes, also known as "white } \\
\text { blood cells." There are different types of } \\
\text { white blood cells; some form a part of the } \\
\text { adaptive immune response, while others } \\
\text { play a key role in innate immunity. Among } \\
\text { this latter group are a class of cells called }\end{array}$ \\
\hline
\end{tabular}

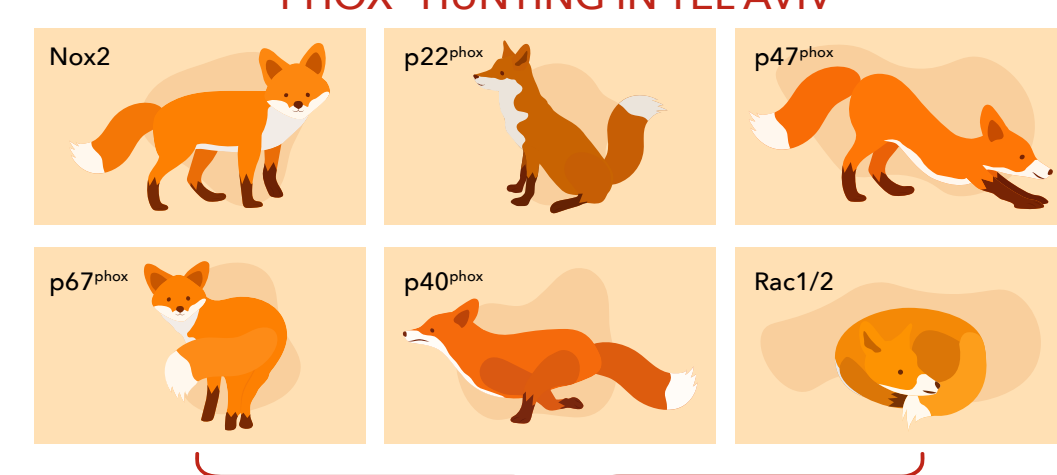

ASSEMBLED NADPH OXIDASE COMPLEX $\mathrm{NADPH}+2 \mathrm{O}_{2}=2 \mathrm{O}_{2}+\mathrm{NADP}^{+}+\mathrm{H}^{+}$

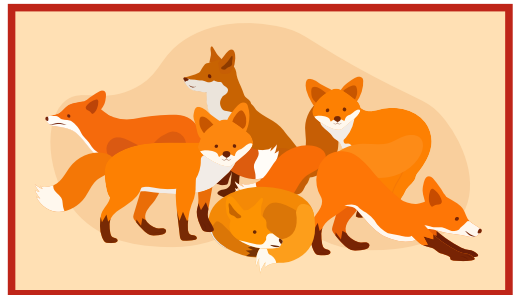

Specifically, Professor Pick has studied the complex pathways by which leucocytes produce ROS to destroy pathogens. the immune dangerous tool: if not carefully regulated, ROS can damage the body's own tissues. Using ROS against pathogens while simultaneously preventing damage to the body's cells is a delicate balancing act.

In phagocytes, the production of ROS is driven by an enzyme complex called NADPH oxidase. This enzyme takes its name from its ability to create superoxide from oxygen by using a molecule called NADPH, as an electron donor. Superoxide is then converted to hydrogen peroxide, which effectively destroys pathogens engulfed by phagocytosis, sometimes with the aid of

In many areas of biological research, is the experiment is conduchniques - tha of living cells or organisms (in contrast to in vivo studies, which do involve using living cells or organisms). In vitro work a number of advantages; for example, conditions can often be controlled more easily, and experiments are carried out with greater accuracy and speed.

In the early 1980s, Professor Pick, together with laboratory colleagues, developed a "cell-free system" for studying the activity of NADPH oxidase. The foundation of this system was NADP oxidase taken from unstimulated phagocytes (i.e. those that were not at a later stage, by assembling the system from a collection of proteins known as "recombinant" because they wer generated by molecular biology methods into the functioning enzyme. Superoxide production could be induced fully in vitro by a simple chemical activator, such as arachidonic acid (a fatty acid present in phagocytes).

The cell-free system allowed Professor Pick together with other researchers to identify and describe the different parts of the NADPH oxidase enzyme in great detail. Crucially, the investigators found that NADPH oxidase is composed of two key parts: a protein (known as cytochrome superoxide, and a second piece which

p67 phox peptides inhibit NADPH oxidase

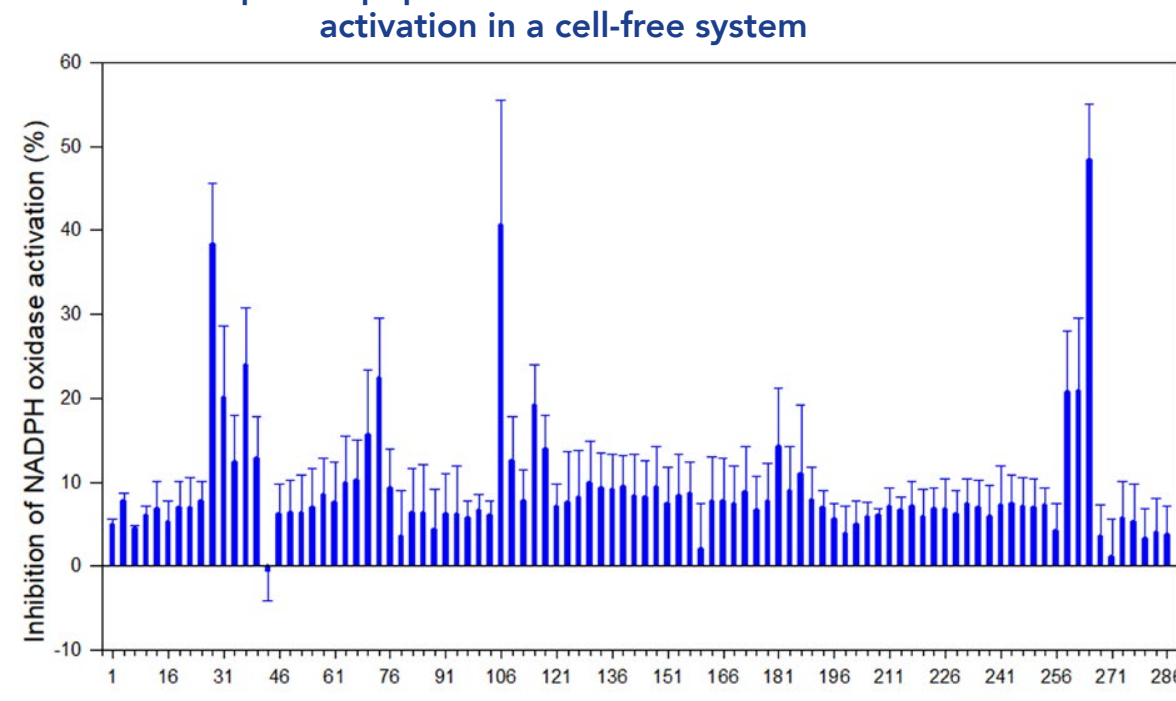

Position of amino-terminal residue of peptide in the sequence of $p 67^{\text {phox }} \mathrm{N}$-terminus

tells the protein what to do and when to do it. This knowledge offered the key to an treatments for the disease.

REVEALING THE STRUCTURE OF A VITAL ENZYME

normal cytochrome part; however, cytosolic components.

In one important discovery, Professor Pick found that one of the key cytosolic components is a protein called $\mathrm{Rac}^{2}$. Rac plays a vital role in activating NADPH

Professor Pick was one of the first cytochrome and one of cytosolic parts of

In phagocytes, ROS play a paramount role in the destruction of pathogens: a process at the core of innate immunity.

"instructor" section of the enzyme was actually composed of different parts, called cyposolc components, varing oxidase, Professor Pick's work has helped to reveal the causes of some forms of CGD Indeed, some patients with CGD have NADPH oxidase with

The catalytic subunit of cytochrome $b_{558}$ is Nox2 (gp91phox)

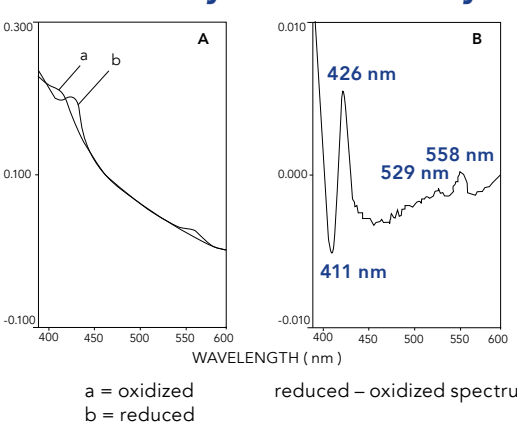

Macrophage membrane the enzyme, known as p67phox, together; once assem bod, the pnzyme can catalyse

Following this discovery, Professor Pick's Peveloped into two separate Pick and colleagues developed a novel method called "peptide walking."4

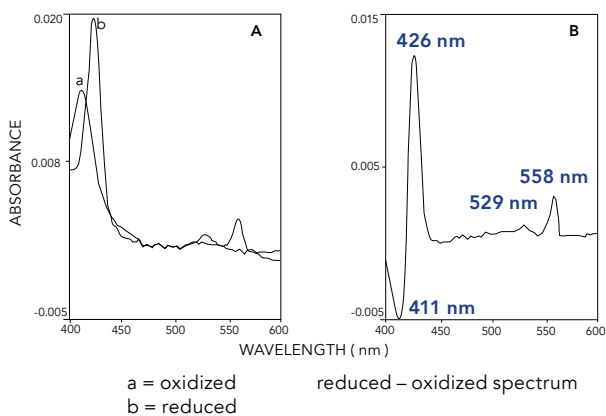

Purified cytochrome $b_{558}$ dimer 


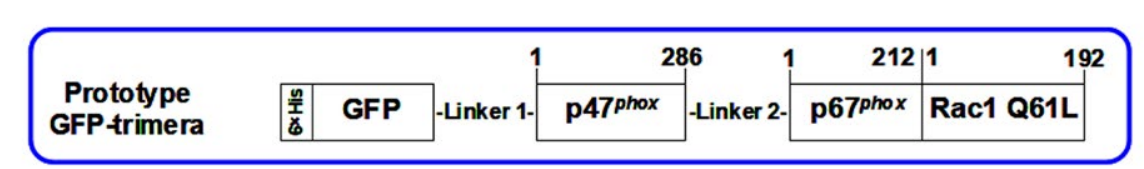

pefoming toved to be capable of cytosolic components in virginal the need for those components to be present With these abilities, the trimeras

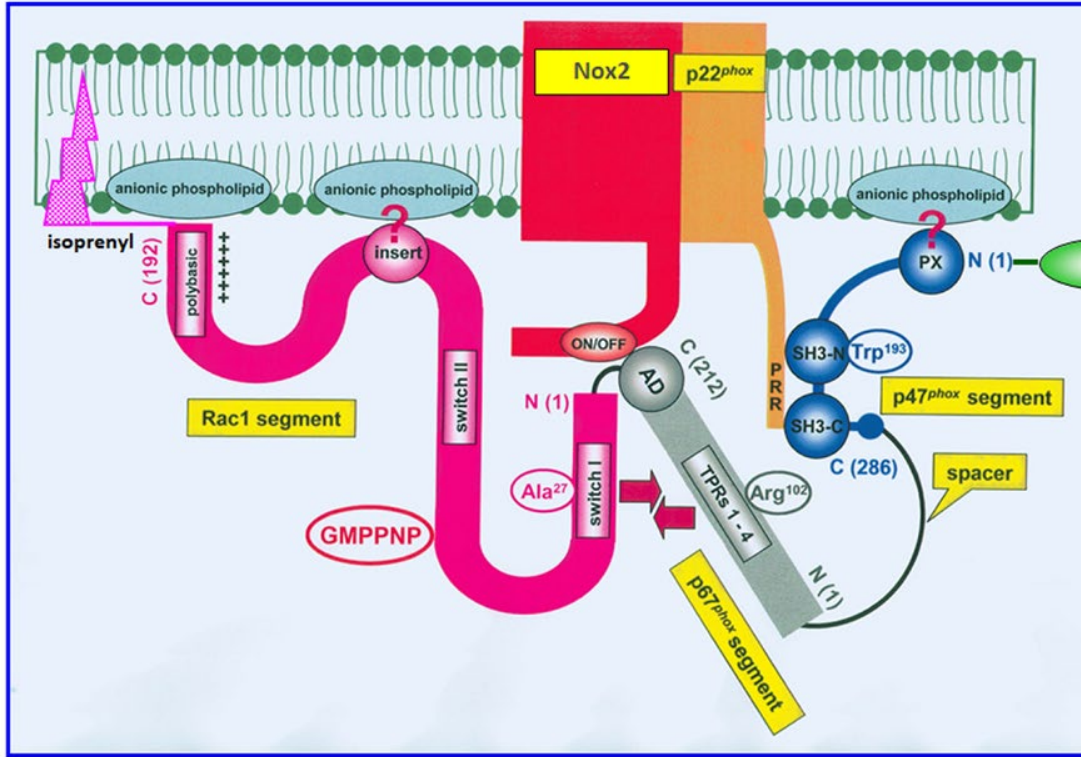

The cell-free system allowed Professor Pick to identify and describe the different components of the NADPH oxidase enzyme complex in great detail.

Peptides are the building blocks of proteins. When applied to this research, peptide walking involves breaking down NADPH oxidase proteins into their component peplides. This allows the sites", represented by specific "eptides in the function of each component and of the enzyme as a whole.

In contrast to CGD, there are other diseases in which too much ROS is produced. By using peptide walking, Professor Pick and his colleagues were as potential candidates for the design of drugs that block the activity of the enzyme. Switching off the enzyme by blocking "active sites" on one of its components by peptides would be an effective way to limit production of celdamaging ROS

In the second research strand, Professor Pick contributed to establishing that a cytochrome), is the only part of NADPH oxidase that performs the catalytic action of the enzyme in generating superoxide. This was proven by removing the cytosolic components of the enzyme and replacin them with certain lipids (fats), known as phospholipids, which were found capa of making cytosolic components.

BUILDING TRIMERAS

This research allowed Professor Pick and his colleagues to have a detailed function of NADPH oxidase. As a next step, the researchers decided to create chimeric molecules (chimeras), by sticking together parts taken from different components of the enzyme. In fact, the team created what they termed "trimera", meaning a chimera composed of three parts, each taken from a differe cytosolic component of the enzyme ${ }^{6}$ Every part of the trimera was chosen to contain one or more of the "active sites" building blocks of the ris seving as the have become valuable tools in screening production of ROS.

Most recently, Professor Pick has focused Nox $2^{2}$. The evidence gathered showed that, at the molecular level, "activated" state when ROS production is required. In turn, p67 causes Nox2 to change shape, allowing the enzym of superoxide. Understanding more of superoxide. Understanding more Structures will hed light on how ROS created and why in some diseases, an excess of these destructive molecules is generated.

\section{AT THE CORE OF}

NNATE IMMUNITY

ades, Professor Pick's work has shone an ever-brighter light on the complex pathways at the core of our innate immunity. As well as broadening understanding of the role of NADPH

oxidase and ROS in tackling pathogens, and his colcaried out by Professor Pick for the dol agues has built a foundation for the development of treatments for His work is a perectexanple of the is work is a perfect example of the and clinical medicine (these days called "translational research") Just as an example, the design of the very basic "cell-free system" led to the discovery of the cytosolic components and this led, as in a chain reaction, to the discovery CGD - namely, genetic mutations in three crucial cytosolic components. His recent work on the p67phox-Nox2 interaction also led to the elucidation of the cause of a form of CGD due to a mutation of a single amino acid in Nox2. In future, the research described here will continue to inspire new routes for investigation into our ability to fight off disease and will generously supporting basic research. potential drug treatments for overcytosolic component p67phox, and p67phox changes from a "resting" to an serious diseases, inclualing CGD and of the genetic causes of some types of the complex and delicate systems behind

\section{Behind the Research}

\section{Dr Edgar Pick}

E: epick@tauex.tau.ac.il $\quad$ T: $+972-36419833 \quad$ T: $+972-505698254 \quad$ W: $h$ ttps:///orcid.org/0000W: http://expertscape.com/au/nadh,\%20nadph\%200xidoreductases/Pick,\%:20Edgar W: Whtps://www.scopus.com/authid/ detail.uri?authorld $=7005824890$

\section{Research Objectives}

series of findings made by Edgar Pick's research group over the last four decades has significantly contributed to the elucidation of the structure and function of the superoxide generating NADPH oxidase of phagocytes.

\section{Detail}

Dr Edgar Pick

75 Einstein Street, Apt. 3
Tel Aviv 6910227 , Israel

Bio

Dr Edgar Pick graduated with an M.D. Medical School in Jerusalem in 1965.

He completed postdoctoral training

ind Research Found Scripps Clinic

(USA), (1965-1967) and at the Institute

of Dermatology, London (UK), (1967-

1970). He graduated with a Ph.D. at Dre University of London (UK) in 1970.

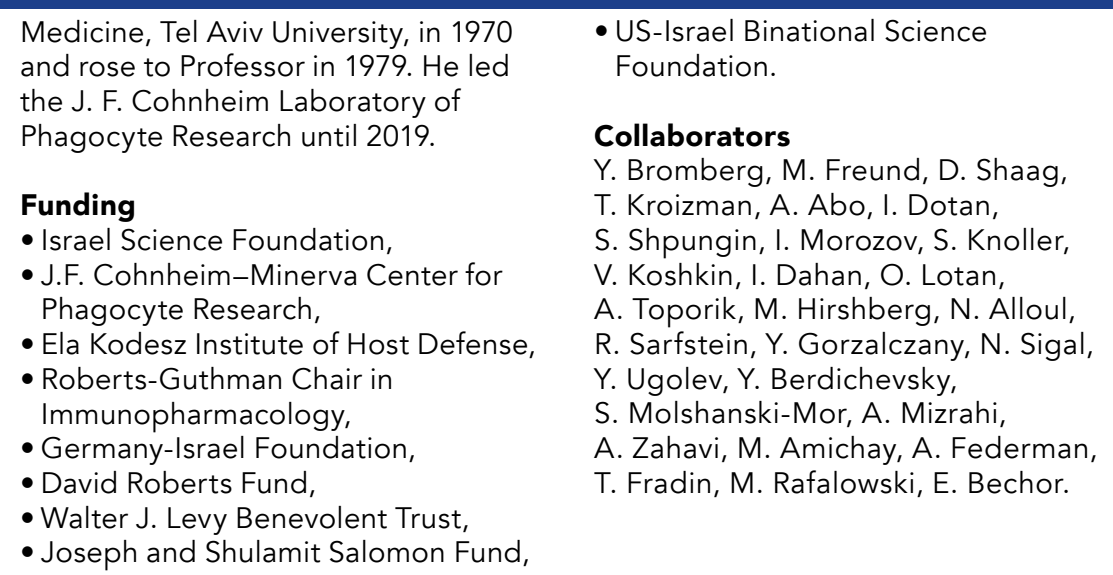

\section{References}

1. Pick, E. 2020. Cell-Free NADPH Oxidase Activation Assays Deleo (eds), Neutrophil: Methods and Protocols, Method in Molecular Biology, vol. 2087:325-411.

2. Pick, E. 2014. Role of the Rho GTPase Rac in the activation of the phagocyte NADPH oxidase:

Outsourcing a key task. Small GTPases 5, e27952. phagocyte membrane is sufficient for the induction of NADPH oxidase assembly. J. Biol. Chem. 275:400734008 Dahan, I \& Pick, E. 2012. Strategies for identifying synthetic "All that you did and did not want to know about $N$ a inhibitory peptides." Cell. Mol. Life Sci. 69:2283-2305. 5. Koshkin, V. \& Pick, E. 1993. Generation of superoxide by purified and re-lipidated cytochrome $b_{555}$ in the absence of

p p4 $7^{\text {phox }}$-p $67^{\text {phox }}$-Rac1 J. Biol. Chem. 285:25485-25499.

7. Fadili, T, et al. 2018. Binding of p 67 bor to Nox2 is . p67 phox. J. Leukoc.

2020. p67phox binds to a newly identified site in Nox2 following the disengagement of an intramolecular bond-Canaan sighted? J. Leukoc Biol.

\section{Personal Response}

In your opinion, what should be the current research

II Innate immunity covers many areas. These days, in subject to which you should dedicate your "scientific life". I always felt a special affinity for a reductionist approach, out of the conviction that a system which is excessively multifactorial is difficult to grasp, unless you are a computer. This is the reason for instinctively choosing systems consisting of molecules and I
stayed away from cells and organisms. I think that the mechanism of ROS generation and regulation will remain central themes in innate immunity research also in the future. However, the unprecedented possibilities to see molecules, the availability of molecule modelling offered by bioinformictics will radically change the "looks" of the field. I would like "to witness resolving the structures of my two great "loves": Nox 2 and p67pox. However, science, like life, research so special is that the future is unpredictab. Finally, it is my dream that NADPH oxidase research will be considered worthy of a Nobel Prize, just as its innate immunity "cousins", Nitric Oxide and the Toll-
like receptors, were. 